\title{
IMPLANTAÇÃO E CONSOLIDAÇÃO DE UM PÓLO TECNOLÓGICO: O CASO DE SÃO JOSÉ DOS CAMPOS*
}

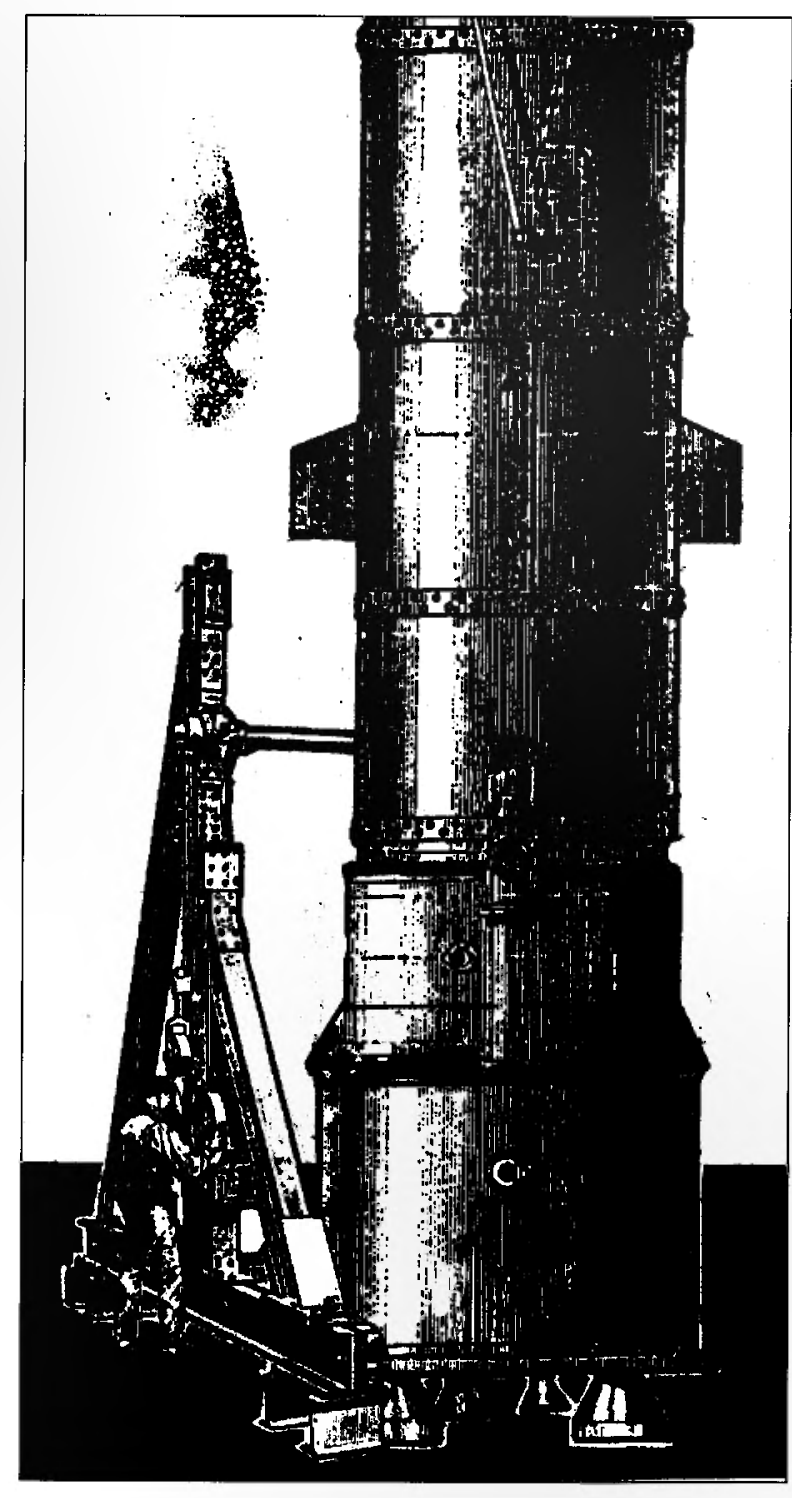

José Adelino de Medeiros

Coordenador do projeto "Pólos Tecnológicos" (convênio CNPq-USP/Instituto de Estudos Avançados), professor convidado da FEAUUSP e diretor técnico da ANPROTEC.

\section{Sérgio Alves Perilo}

Analista de Desenvolvimento Científico do Instituto de Pesquisas Espaciais (INPE).

\begin{abstract}
RESUMO: Uma interação apropriada entre ensino, pesquisa e indústria, respeitadas as particularidades de cada atividade e os respectivos periodos de maturação, tornaram São José dos Campos um dos mais importantes exemplos de desenvolvimento tecnológico-industrial do Brasil. Constatou-se o esforço deliberado de pessoas e instituições interessadas em concentrar na cidade uma capacitação nos setores aeroespacial e bélico, o que resultou na criação e consolidação de um tipo de pólo tecnológico discutido na literatura especializada. Este artigo identifica $e$ analisa os mecanismos que levaram ao estágio atual do desenvolvimento da cidade e discute o processo de transformação de pesquisas em inovações tecnológicas.
\end{abstract}

PALAVRAS-CHAVE: Pólos tecnológicos, parques tecnológicos, empresas de base tecnológica, centros de inovação, setor aeroespacial.

\section{INTRODUÇÃO}

A capacitação tecnológica que se gerou e consolidou em São José dos Campos (SJC) teve sua origem no interesse governamental em desenvolver as áreas aeronáutica, espacial, bélica e eletrônica avançada. Trata-se de setores considerados estratégicos para o desenvolvimento nacional e, portanto, tiveram forte apoio governamental via financiamentos diretos ou através de seu poder de compra. Merecem igual destaque a habilidade e o pioneirismo das pessoas que lideravam os projetos. Desde o início houve a preocupação em repassar as tecnologias para a indústria e constatou-se a superáção das barreiras institucionais e burocráticas que ainda hoje existem em diversos centros. Por esses motivos a cidade é citada como um dos mais importantes exemplos de desenvolvimento tecnológico-industrial do país. Seja pela relevância de suas instituições de ensino e pesquisa, seja pelo conjunto de empresas de base tecnológica, seja pela forte interação existente entre a academia e a indústria.

*Artigo apresentado no Seminário Universidade Empresa, promovido pela UFRJ/COPPE, Rio de Janeiro, 5 a 8 de junho de 1989. 
A cidade de São José dos Campos tem projeção internacional e exibe produtos de alto conteúdo tecnológico como aviões, foguetes e satélites, os quais são fruto de pesquisas iniciadas nos anos 50. Adotando a terminologia difundida na década de 80, pode-se afirmar que São José dos Campos constitui um tipo de pólo tecnológico que foi implantado sem necessitar de uma estrutura organizacional formal. Essa estrutura usualmente é concebida para facilitar a interação entre três parceiros: instituições de ensino e pesquisa, indústrias e governo (nos seus diversos níveis). Essa estrutura existia implicitamente, o que valoriza o caso estudado.

A literatura especializada também considera um segundo tipo de pólo tecnológico, que é o inverso do mencionado acima. Nesse caso existe a definição prévia de uma estrutura organizacional, criada para facilitar o aproveitamento do potencial científico-tecnológico local e para promover a articulação entre a academia, a indústria e o governo. Para complementar a discussão descrevese brevemente o conceito de Parque Tecnológico (Science Park). Trata-se de um terceiro tipo de pólo tecnológico. Além da mencionada estrutura organizacional formal, contém terrenos e prédios localizados ao lado das instituições de ensino e pesquisa, destinados a abrigar as indústrias de base tecnológica, as quais interagem com as mencionadas instituições. Esses três tipos de pólo tecnológico estão descritos em Medeiros ${ }^{1}$, onde são discutidos catorze pólos tecnológicos existentes nas diversas regiões do país. Para tornar mais homogênea a classificação de pólos tecnológicos, são definidos três tipos. No pólo tipo 1, inexiste uma estrutura organizacional formal encarregada de facilitar a vinculação das empresas com as instituições de ensino e pesquisa e governo. No pólo tipo 2, constata-se a existência dessa estrutura formal. Finalmente, no pólo tipo 3, que será chamado de Parque Tecnológico, constata-se a existência da mencionada estrutura, além de terrenos e/ou prédios alugados ou vendidos às empresas.

Voltando ao caso de São José dos Campos, neste texto pretende-se explicitar os passos que possibilitaram o surgimento e a consolidação desse importante pólo tecnológico (enquadrado no tipo 1). Para atingir esse objetivo, são analisados dois aspectos de São José dos Campos: 1) os mecanismos que possibilitaram alcançar o presente estágio de desenvolvimento tecnológico-industrial; e 2) o papel de cada um dos parceiros en- volvidos no processo de inovação tecnológica. Para realizar o estudo, os autores optaram por efetuar uma pesquisa exploratória que permitisse obter uma visão aprofundada dos aspectos julgados relevantes. Foi utilizada a técnica conhecida como "estudo de caso" que, embora não permita efetuar generalizações, possibilita a identificação de experiências relevantes e atende aos objetivos fixados anteriormente. Na condução do "estudo de caso" foram realizadas entrevistas com três conjuntos de pessoas: representantes do setor de ensino e pesquisas; representantes de empresas; e pessoas que participaram do desenvolvimento científico-tecnológico de São José dos Campos (cientistas, políticos e industriais). As informações obtidas nas entrevistas foram complementadas por uma revisão bibliográfica, pela consulta a artigos sobre a experiência da cidade e pela utilização de dados obtidos junto à prefeitura.

No levantamento de dados e informações, três aspectos principais mereceram ênfase:

a) visão histórica e principais indicadores do perfil e desempenho de São José dos Campos;

b) formação e consolidação do setor de ensino e pesquisas, havendo realce para o Centro Tecnológico da Aeronáutica (CTA) e para o Instituto de Pesquisas Espaciais (INPE); $\mathrm{e}$

c) formação, perfil e desempenho de onze empresas da cidade diferenciadas no que diz respeito a tamanho, motivações para a sua criação, apoio governamental e tempo de existência.

As empresas entrevistadas estão listadas a seguir segundo a quantidade de funcionários, começando-se pelas de maior número:

1. (EMBRAER) Empresa Brasileira de Aeronáutica S.A.

2. (AVIBRAS) Avibrás Indústria Aeroespacial S.A.

3. (ENGESA) Engesa Engenheiros Especializados S.A.

4. (TECNASA) Tecnasa Eletrônica Profissional S.A.

5. (AMPLIMATIC) Amplimatic S.A. Indústria e Comércio

6. (ORBITA) Orbita Sistemas Aeroespaciais S.A.

7. (COMPOSITE) Composite Tecnologia Ind. e Com. Ltda.

1. MEDEIROS, J.A. Brazilian Science Parks, Technopoles and Innovation Centers in 1988: Models and outcomes. CNPq/Agência Regional São Paulo, Relatório Técnico $\mathrm{n}^{\mathrm{0}} 4 / 89$ 
8. (ABC) ABC Sistemas Eletr. S.A. Divi.Simulad. e Aviônica

9. (ENGESPAÇO) Engespaço Ind. e Com. Ltda. 10.(QUANTUM) Quantum Engenh. de Mat. e Inform. Ltda.

11.(IMAGEM) Imagem Sensor. Remoto S/C Ltda.

\section{ASPECTOS HISTÓRICOS E ECONÔMICOS}

São José dos Campos está situada a Nordeste do Estado de São Paulo, a $600 \mathrm{~m}$ de altitude; ocupa uma área de $1.118 \mathrm{~km}^{2}$ e localiza-se a aproximadamente $90 \mathrm{~km}$ da capital paulista. Apresenta características que a tornam um local adequado para a instalação de praticamente todos os tipos de empresa, podendo-se realçar:

a) localização no eixo Rio-São Paulo;

b) disponibilidade de energia elétrica em abundância e lençol freático rico;

c) proximidade de grandes mercados consumidores;

d) boa rede viária;

e) clima agradável; e

f) boa topografia.

Esses fatores, aliados à existência, até o início da década de 70 , de terrenos relativamente baratos e de uma infra-estrutura urbana adequada para absorver um contingente operário que eventualmente para lá se dirigisse, atraíram empresas, principalmente multinacionais, que se instalaram basicamente ao longo da Via Dutra.

Ao longo de sua existência, São José dos Campos foi protagonista de vários ciclos econômicos. O primeiro deles foi o do Café (1830-1930), seguido pelo Ciclo da Pecuária e da Fase Sanatorial (1920-1950), quando a cidade se tornou um importante centro de tisiologia. $\mathrm{O}$ ciclo industrial se consolidou a partir de 1950. Até 1945, a cidade apenas possuía empresas industriais nos ramos de cerâmica e têxtil. Em 1946, começou a funcionar a primeira grande fábrica fora dos ramos têxtil e cerâmico, a Rhodia Indústrias Químicas e Têxteis S.A. Durante a década de 50 se instalaram na cidade principalmente as empresas multinacionais de médio ou grande porte, como Johnson \& Johnson, Ericsson, Kanebo e General Motors. Durante a década de 60 , começaram a se instalar as empresas nacionais que mais tarde comporiam os parques aeronáutico e bélico, como Avibrás e Embraer.

Em decorrência desse surto industrial, que se estende até o presente, São José dos Campos conta com cerca de 450.000 habitantes, 540 indústrias, é o quarto município paulista em arrecadação de ICM e o quinto município do Brasil em consumo de energia elétrica. Ao longo do desenvolvimento da cidade, não houve uma preocupação da prefeitura em fornecer incentivos diretos para a instalação de empresas, mas sim a de prover a infraestrutura básica para a instalação das empresas e a formação e o abrigo de seu contigente operário.

$O$ parque industrial que se consolidou na cidade, para os fins deste trabalho, pode ser dividido em três grandes blocos:

a) empresas multinacionais de médio e grande porte, de base tecnológica, que vivem principalmente da tecnologia de suas matrizes;

b) empresas nacionais de setores tradicionais; $\mathrm{e}$

c) empresas nacionais, de base tecnológica, para as quais foi importante a interação com o CTA e o INPE.

Esse parque industrial não tem uma especialização definida, embora as empresas nacionais de base tecnológica, que são o foco deste trabalho, se concentrem nos ramos aeroespacial, bélico e de eletrônica avançada. O setor industrial de São José dos Campos, como um todo, oferece atualmente mais de 60.000 empregos. Deve-se observar que, se consideradas suas subsidiárias instaladas em São José dos Campos, o número de funcionários do conjunto de empresas entrevistadas ultrapassa 20.000, ou seja, mais de um terço do total de empregados de todas as empresas da cidade.

\section{O SETOR DE ENSINO E PESQUISAS}

\section{Centro Técnico Aeroespacial (CTA)}

O envolvimento do Brasil na Segunda Grande Guerra gerou no recém criado Ministério da Aeronáutica a conviç̧ão de que não era possível enfrentar ação militar inimiga na total dependência da utilização de equipamentos e material bélico importado. Mostrou também que a formação de um parque aeronáutico no Brasil tinha como pré-requisito a formação de pessoal. Como forma de incrementar o nível científico e tecnológico da aeronáutica nacional e atender a uma antiga reivindicação da corporação militar, foi concebida a instalação de um centro de capacitação científica e tecnológica dentro do próprio Ministério da Aeronáutica. A mencionada escola foi idealizada 
e posteriormente implantada, tendo como modelo o Massachussets Institute of Technology (MIT). Para a concepção e implementação da estrutura operacional e delineamento dos currículos dos cursos dessa escola, que receberia o nome de Instituto Tecnológico da Aeronáutica (ITA), recorreuse à colaboração do Professor Richard H. Smith, então chefe do Departamento de Aeronáutica do MIT, que viria a ser o primeiro reitor do ITA.

A escolha da localização do futuro centro aeronáutico se norteou pelo princípio de que ele deveria ser fora das grandes cidades, mas razoavelmente próximo para permitir o intercâmbio de professores e técnicos com outras escolas de nível superior, instituições de $P \& D$ e com a indústria. São José dos Campos foi escolhida devido à energia elétrica abundante, proximidade do porto de Santos, existência de terras, proximidade da cidade de São Paulo e excelente clima ${ }^{2}$. Além disso, havia facilidade de comunicações (a Via Dutra já estava em construção), excelente topografia e disponibilidade de terrenos.

O ITA, primeiro dos institutos do CTA, foi inaugurado em janeiro de 1950. Nos primeiros anos de funcionamento dessa instituição, grande parte dos professores vinha dos E.U.A. e alguns da Europa. Os cursos do ITA exigiam dedicação exclusiva dos alunos, que moravam em alojamentos da escola. Como afirma Strauss", "como concepção inovadora e ambiciosa de ensino superior, o ITA serviu de modelo e inspiração a progressos setoriais mais tarde ocorridos no anacrônico sistema universitário brasileiro". Até dezembro de 1989, 3347 engenheiros graduaram-se pelo ITA.

O Instituto de Pesquisa e Desenvolvimento (IPD), o segundo dos institutos do CTA, foi criado em 1954. Já na década de 60 o IPD passou a realizar projetos de grande porte e o principal deles foi o IPD-6504, que desenvolveu o projeto e fabricou protótipos de um avião que posteriormente viria a ser fabricado pela Embraer com o nome de Bandeirante. As atividades de desenvolvimento no campo espacial e de incentivo à produção, que tiveram origem no IPD na segunda metade da década de 60, levaram à formação de dois novos institutos do CTA: o Instituto de Atividades Espaciais(IAE) e o Instituto de Fomento e Coordenação Industrial (IFI). Esses institutos foram inaugurados respectivamente em 1973 e 1974 . Na década de 80 viria o quinto instituto, o Instituto de Atividades Avançadas (IEAv), que realiza pesquisas em física de baixa e alta energia, física de plasmas, lasers de precisão, interação laser-plasma e eletrônica digital. Com a definição da Missão Espacial Completa Brasileira (MECB), em 1980, o CTA também se tornou responsável, através do IAE, pelo desenvolvimento do Veículo Lançador de Satélites (VLS), que é um vetor capaz de lançar cargas de até $150 \mathrm{~kg}$ a uma altitude de aproximadamente $750 \mathrm{~km}$.

Ao longo de sua existência, o CTA tem procurado incrementar o aproveitamento industrial de suas tecnologias e melhorar o patamar tecnológico da indústria nacional. Prova disso foi a criação do IFI em 1974, que é um instituto totalmente dedicado ao desenvolvimento e à consolidação das indústrias aeronáutica e espacial e à homologação de seus produtos. O desenvolvimento tecnológico realizado pelo CTA já viabilizou a criação de várias empresas, das quais a Embraer é o exemplo mais marcante. Além disso, o CTA prestou uma contribuição significativa para a elevação do nível de qualificação da indústria nacional de um patamar automobilístico para um patamar aeronáutico.

Merece também realce o papel do CTA na formação de recursos humanos altamente qualificados, ingrediente fundamental e decisivo na concepção de um pólo tecnológico. Os engenheiros do ITA ocupam postos de destaque no governo e nas empresas, em várias regiões do país e em diferentes setores. Apesar desses resultados, o CTA, presentemente, não se tem envolvido em grandes projetos mobilizadores, com características interdisciplinares, como foi o caso do projeto do Bandeirante. Além disso, pelo seu próprio crescimento, acredita-se que o CTA tenha perdido muito de sua flexibilidade. é interessante observar, como exemplo, que hoje o Centro sente grande dificuldade em contratar os engenheiros que são formados por ele mesmo no ITA, pela falta de competitividade dos salários oferecidos.

\section{Instituto de Pesquisas Espaciais (INPE)}

O INPE é a principal instituição civil brasileira voltada para a realização de atividades espaciais no país. É um órgão autônomo, vinculado à Secre-

2. SMITH, R. H. The new center of technical aeronautics and the Aeronautics Institute of Technology at São José dos Campos - Brasil. S. 1., 1945, p.5 (publicação avulsa).

3. STRAUSS, J. V. "ITA: um exemplo a ser seguido". In: Revista IBM, nº 10, 1982, p. 2 (separata). 
taria Especial de Ciência e Tecnologia da Presidência da República e concentra a maior parte de suas atividades em São José dos Campos. Foi criado em 1961 como um Grupo de Organização da Comissão Nacional de Atividades Espaciais (GOCNAE), em decorrência da postura do Governo Federal e de um grupo de cientistas brasileiros de que o Brasil não deveria se omitir de participar do movimento das principais potências mundiais em direção ao estudo e aproveitamento do espaço.

Os objetivos básicos que orientaram a formação do GOCNAE (que passaria a ser conhecida apenas como (NAE) foram:

a) criar uma organização que pudesse realizar atividades relacionadas com a utilização do espaço; e

b) preparar um núcleo de pesquisadores capaz de tratar dos problemas espaciais e de interagir com grupos de estudos semelhantes de outros países.

A CNAE foi idealizada e implantada como entidade civil, fora do Ministério da Aeronáutica, em decorrência do argumento, ainda válido nos dias de hoje, de que as trocas de informações com órgãos civis de outros países seriam fortemente prejudicadas se ela tivesse caráter militar, o que, por sua vez, comprometeria um de seus mais importantes objetivos, que era o de promover esse intercâmbio. Os dois principais motivos que levaram à instalação do GOCNAE em São José dos Campos foram a origem de seus membros, quase todos eles provenientes do CTA, e a existência de terreno para a construção de uma sede para o Grupo, também cedido pelo CTA.

Em 1971 foi extinto o GOCNAE, que foi sucedido pelo Instituto de Pesquisas Espaciais (INPE), unidade subordinada ao Conselho Nacional de Desenvolvimento Científico e Tecnológico-CNPq. Em agosto de 1985, com a criação do Ministério de Ciência e Tecnologia (MCT), o INPE passaria a ser um órgão diretamente vinculado àquele Ministério. Em 1989, com a transformação do MCT em Secretaria Especial de Ciência e Tecnologia, o INPE passou a ser vinculado a essa Secretaria.

As atividades do INPE podem ser divididas em três grupos principais:

1) ciências espaciais e atmosféricas;

2) aplicações espaciais (basicamente meteorologia e sensoreamento remoto); $\mathrm{e}$

3) engenharia e tecnologia espaciais.

Detalhando essa última área, enfatizada a par- tir de 1980 como parte da MECB, nota-se a preocupação do INPE com o desenvolvimento e fabricação de satélites e com o segmento solo associado. Trata-se de um programa de desenvolvimento, fabricação e lançamento de quatro satélites (dois de coleta de dados e dois de sensoriamento remoto) a partir de uma base construída em território nacional, utilizando um veículo lançador a combustível sólido também desenvolvido no país.

Atualmente, além da MECB, o INPE está desenvolvendo e deverá fabricar em um programa de cooperação com a China, dois satélites avançados de sensoriamento remoto, que deverão ser lançados em 1993 e 1995, utilizando lançadores chineses. Tanto a MECB como o programa de cooperação com a China têm como diretriz uma ampla participação da indústria nacional. A meta é que ao final desses programas existam no país empresas qualificadas para o fornecimento de vários equipamentos e subsistemas para satélites. Para a realização de seus programas, o INPE conta com cerca de 1700 funcionários, dos quais 800 têm formação superior.

Outra atividade de destaque do INPE é a formação de recursos humanos ao nível de pós-graduação. No momento, são ministrados cursos nas áreas de ciência espacial, meteorologia, sensoriamento remoto e eletrônica e telecomunicações. $\mathrm{O}$ INPE já formou 540 mestres e 27 doutores nessas áreas. Além dos cursos de mestrado e doutorado, existem também programas de treinamento ao nível de pós-graduação e aperfeiçoamento em diversas áreas. Tanto no INPE como no CTA constata-se uma ênfase especial na formação de recursos humanos.

\section{Outras Instituições de Ensino}

Além do ITA, que ministra cursos de graduação e pós-graduação, e do INPE, com cursos de pós-graduação, São José dos Campos conta com outros sete estabelecimentos de ensino superior, um estadual e seis particulares, sendo dois de engenharia. Nesses estabelecimentos, além dos cursos de engenharia, são mantidos cursos de direito, economia, filosofia, odontologia e serviço social. No segundo grau, São José dos Campos conta com 15 estabelecimentos, dos quais merece destaque a Escola Técnica Prof. Everardo Passos (ETEP), que ministra ensino técnico industrial em mecânica e eletrônica. São José dos Campos conta 
ainda com a Escola SENAI "Santos Dumont", que ministra cursos de aprendizagem industrial, especialização e qualificação profissional em cerca de 30 especialidades. O SENAI também oferece cursos dentro das próprias empresas.

\section{DESCRIÇÃO E ANÁLISE DAS EMPRESAS ENTREVISTADAS}

Nesta seção serão apresentados os dados e informações sobre onze empresas de São José dos Campos que foram estudadas com maior detalhe pelos autores. Os dados de caráter geral estão sumarizados no quadro I. Analisando-se o referi- do quadro, é possível constatar que as empresas maiores se formaram na década de 60 e as menores na década de 80 . A exceção é a Engesa, que também surgiu na década de 60 , mas que apenas em 1975 implantou sua unidade em São José dos Campos. O que se pode inferir a partir dessa constatação é que a década de 60 representou um marco importante para a instalação de empresas na cidade e esse fenômeno parece estar se renovando na década de 80 . Nota-se ainda que as empresas grandes exportam uma fração significativa de seu faturamento (às vezes a quase totalidade), o mesmo não acontecendo com as empresas menores. De um modo geral, as empresas

\section{Quadro I}

\section{Perfil Das Empresas Entrevistadas}

\section{(Dados de 1987)}

\begin{tabular}{|c|c|c|c|c|c|c|}
\hline $\begin{array}{l}\text { Nome da } \\
\text { Empresa }\end{array}$ & $\begin{array}{c}\text { Data } \\
\text { Fundação }\end{array}$ & $\begin{array}{c}\text { Origem do } \\
\text { Capital }\end{array}$ & $\begin{array}{c}\quad № \text { de } \\
\text { Funcionários }\end{array}$ & $\begin{array}{l}\text { Exportaçōes } \\
\text { (\% do Fat.) }\end{array}$ & $\begin{array}{l}\text { Vendas Gov. } \\
\text { (\% do Fat.) }\end{array}$ & $\begin{array}{l}\% \text { Fatur. } \\
\text { Inves. P\&D }\end{array}$ \\
\hline EMBRAER & 1969 & $\begin{array}{l}\text { Governot } \\
\text { Inc.Fiscais }\end{array}$ & $9.027^{1}$ & 65 & 21 & 8.9 \\
\hline AVIBRÁS & 1961 & Sócios & $5.000^{1}$ & 98 & 2 & 10 \\
\hline ENGESA & 1975 & Grupo Engesa & $2.500^{2}$ & mais de 90 & menos de 90 & n.d. \\
\hline TECNASA & 1962 & Sócios & $502^{1}$ & - & mais de 50 & 30 \\
\hline AMPLIMATIC & 1964 & Sócios & $439^{1}$ & 0 & 0 & 7 \\
\hline ÓRBITA & 1987 & Empresas $^{3}$ & 250 & n.d. & n.d. & n.d. \\
\hline COMPOSITE & 1981 & Sócios & 105 & 0 & mais de 80 & n.d. \\
\hline$A B C$ & 1984 & grupo $A B C$ & 69 & 0 & 100 & n.d. \\
\hline ENGESPAÇO & 1983 & $\begin{array}{c}\text { Fundação } \\
\text { Privada }\end{array}$ & 16 & 0 & 100 & n.d. \\
\hline QUANTUM & 1987 & Sócios & 1 & 0 & - & n.d. \\
\hline IMAGEM & 1986 & Sócios & 1 & 0 & 30 & 20 \\
\hline
\end{tabular}

1. Somente na principal empresa do grupo; 2. Fábrica São José; 3. ENGESA (40\%), EMBRAER (40\%), ESCA (11\%), IMBEL (5\%) e PARCON (4\%); n.d. não disponível 
investiram significativamente em $\mathrm{P} \& \mathrm{D}$, embora, no caso das empresas menores, esse investimento não fique explícito, uma vez que os próprios sócios costumam realizar essas atividades.

Analisando-se o desempenho das empresas maiores, pode-se concluir que o poder de compra do governo, representado principalmente pelo Ministério da Aeronáutica, foi importante e às vezes decisivo para criação e/ou consolidação dessas empresas. No entanto, ao longo do tempo, as exportações têm se tornado a principal fonte de renda dessas empresas, que diminuíram assim a sua dependência em relação ao governo mas passam a depender dos mercados externos. Nesse caso surge uma nova fonte de problemas, constatando-se, em alguns casos, interrupção nas vendas devido a fatores internacionais, fora do controle da empresa.

Ainda com relação às empresas maiores, ficou evidenciada a tendência de elas assumirem uma postura de montadoras ou integradoras do produto final. Elas detêm o projeto global dos produtos e promovem, cada vez mais, a horizontalização de sua produção, com as empresas menores fornecendo partes ou equipamentos. Essa horizontalização que vem acontecendo nas empresas maiores, associada a uma constante preocupação com a nacionalização de fornecedores, tem favorecido a implantação de novas empresas na cidade.

As empresas em que realizamos entrevistas, principalmente as maiores, apesar de investirem significativamente em $P \& D$, também compram tecnologia. No entanto, nesses casos, existe uma preocupação com a transferência e absorção da tecnologia comprada, o que fica facilitado pelo forte componente de engenharia que existe nessas empresas. A preocupação com a nacionalização tem um caráter estratégico, uma vez que a maioria das empresas atua em áreas sensíveis, onde a venda ou não da tecnologia depende da conveniência política dos países exportadores.

No que diz respeito à origem do capital para a formação das empresas estudadas, à exceção da Embraer, que é uma empresa estatal de capital misto, todas as outras tiveram em seus próprios sócios (que às vezes podem ser outras empresas) a fonte de capital para a sua instalação. Nenhuma delas se associou a um banco como forma de obter os recursos para a sua instalação. Tendo em vista a discussão sobre pólo tecnológico que presentemente ocorre na literatura internacional, nesta pesquisa também houve a preocupação de identificarem-se os mecanismos de criação de empresas e os fatores que levaram à sua instalação em São José dos Campos. Uma descrição esquemática desses mecanismos e fatores é apresentada no quadro II. Como a pesquisa foi conduzida na forma de um estudo de caso, provavelmente existem outros mecanismos de criação de empresas que não foram detectados. Contudo, houve a preocupação em escolher empresas com perfil bastante diferenciado.

O primeiro caso apresentado no quadro II representa a situação em que alguns pesquisadores vislumbraram algum nicho de mercado, associaram-se e criaram uma empresa para aproveitar essa oportunidade. Nesse caso os pesquisadores freqüentemente continuaram trabalhando na instituição de pesquisa até que a empresa se tornasse lucrativa e estável.

No segundo caso, os projetos desenvolvidos no CTA foram "transformados" em novas empresas. Um exemplo típico é a Embraer. O projeto era um avião turboélice para aviação regional, de fuselagem metálica, para até 19 passageiros, que seria mais tarde produzido e comercializado pela empresa com o nome de Bandeirante. A Embraer foi constituída em 1969 basicamente para produzir esse avião em série. No caso da $A B C$, ela foi criada para fabricar simuladores de avião para a FAB, utilizando tecnologia básica desenvolvida pelo CTA.

No terceiro caso abordado no quadro II, as empresas foram atraídas pelas condições favoráveis oferecidas por São José dos Campos. Dentre essas condições, as mais citadas foram a existência de terrenos com boa topografia e, à época, com bons preços, além das boas condições sócio-econômicas, geográficas e de infra-estrutura.

No quarto caso, representado pela Órbita, a empresa foi criada por consorciamento de outras empresas. O quinto caso, representado pela Engespaço, mostra uma empresa que foi criada a partir de uma fundação ligada ao INPE para produzir, em escala pré-industrial, subprodutos de pesquisa desse Instituto para os quais não se encontraram parceiros industriais interessados.

Finalmente, o sexto mecanismo que possibilita a criação de empresas reflete a maturidade do setor industrial: trata-se de empresas já consolidadas que criaram subsidiárias, as quais, dependendo do caso, horizontalizam ou verticalizam suas linhas de atuação. 


\section{Quadro II Mecanismos que Possibilitaram a Criação de Empresas em São José dos Campos e Fatores que Levaram à Sua Instalação na Cidade}

\begin{tabular}{|c|c|c|}
\hline Mecanismo & Empresa & Fatores para Instalação em São José \\
\hline $\begin{array}{l}\text { 1.Pesquisadores orindos } \\
\text { do Setor de Pesquisa } \\
\text { local criam empresa }\end{array}$ & $\begin{array}{l}\text { AVIBRÁS } \\
\text { TECNASA } \\
\text { COMPOSITE } \\
\text { QUANTUM } \\
\text { IMAGEM }\end{array}$ & $\begin{array}{l}\text { - Pesquisadores continuam a trabalhar no } \\
\text { Instituto de Pesquisa } \\
\text { - Pesquisadores já moram na cidade } \\
\text { - Institutos de Pesquisa são fonte de geração e } \\
\text { entrada de tecnologia no país. } \\
\text { - Institutos de Pesquisa funcionam como ponto } \\
\text { de apoio para novos empresários } \\
\text { - Utilização de laboratórios dos Institutos de } \\
\text { Pesquisa } \\
\text { - Instituto de Pesquisa é cliente e homologa } \\
\text { produto }\end{array}$ \\
\hline $\begin{array}{l}\text { 2. Empresa criada a } \\
\text { partir de projeto } \\
\text { desenvolvido em } \\
\text { Instituto de Pesquisa }\end{array}$ & $\begin{array}{l}\text { EMBRAER } \\
\text { ABC }\end{array}$ & $\begin{array}{l}\text { - Equipes são transferidas para nova empresa } \\
\text { - Utilização de laboratórios do IP } \\
\text { - Instituto de Pesquisa é cliente e homologa } \\
\text { produto }\end{array}$ \\
\hline $\begin{array}{l}\text { 3.Empresas atraídas } \\
\text { pela cidade }\end{array}$ & $\begin{array}{l}\text { ENGESA } \\
\text { ABC } \\
\text { AMPLIMATIC }\end{array}$ & $\begin{array}{l}\text { - Terreno em boas condições de preço e } \\
\text { tomografia } \\
\text { - Boas condições sociais e geográficas da cidade }\end{array}$ \\
\hline $\begin{array}{l}\text { 4. Empresas criadas por } \\
\text { consórcio de empresas } \\
\text { existentes }\end{array}$ & ÓRBITA & $\begin{array}{l}\text { - Empresas consorciadas já têm unidades na } \\
\text { cidade } \\
\text { - Institutos de Pesquisa locais são fontes de } \\
\text { tecnologia }\end{array}$ \\
\hline $\begin{array}{l}\text { 5. Empresas criadas por } \\
\text { Fundação associada a } \\
\text { Instituto de Pesquisa }\end{array}$ & ENGESPAÇO & - Instituto de Pesquisa é fonte de tecnologia \\
\hline $\begin{array}{l}\text { 6. Empresas criam } \\
\text { subsidiárias }\end{array}$ & $\begin{array}{l}\text { AVIBRÁS } \\
\text { EMBRAER } \\
\text { AMPLIMATIC } \\
\text { TECNASA }\end{array}$ & $\begin{array}{l}\text { - Empresa matriz localiza-se em São José dos } \\
\text { Campos }\end{array}$ \\
\hline
\end{tabular}




\section{CONCLUSÕES}

Pode-se dizer que a implantação do CTA, na década de 50, e a instalação do INPE, na década de 60 , foi o germe para a formação do aglomerado de empresas de base tecnológica em São José dos Campos. Quando da instalação desses institutos, havia o objetivo claro de formar recursos humanos altamente capacitados e criar uma competência industrial no ramo aeroespacial no Brasil. Não houve uma estrutura organizacional formal que agregasse os vários parceiros e acelerasse a interação entre eles. Trata-se do primeiro tipo de pólo tecnológico, discutido no início deste texto. Desse modo, não houve apoio gerencial para a instalação dessas empresas nem a formação do aglomerado de empresas ocorreu através de um processo explicitamente coordenado.

No final da década de 80 constata-se que São José dos Campos tem projeção internacional no setor aeroespacial. O desenvolvimento dos projetos de satélite pelo INPE e de um lançador pelo IAE/CTA estão em fase de maturação e o desenvolvimento tecnológico de equipamentos e de subsistemas já está se completando. A exemplo do que ocorreu no passado para o setor aeronáutico, está chegando o momento de se buscar a fabricação em série desses equipamentos, para o que o setor industrial está e continuará sendo chamado a contribuir. $\mathrm{O}$ fato de empresas virem a trabalhar nesse novo segmento, atendendo aos requisitos do setor espacial, certamente terá influência no nível de qualidade, nos procedimentos de fabricação e nas práticas gerenciais correntes nessas empresas. Além da natural evolução do parque industrial da cidade, esse novo conjunto de atividades poderá servir de base a um novo grau de capacitação tecnológica e a uma horizontalização do pólo, com a atuação em áreas ainda não exploradas nele.

$O$ capital de risco, usualmente utilizado na criação de empresas que surgem em virtude da aplicação de novos desenvolvimentos tecnológicos, não esteve presente na formação do aglomerado de empresas de São José dos Campos. No entanto, o poder de compra do Ministério da Aeronáutica em grande parte substituiu esse capital de risco, ao fazer encomendas que acabariam por viabilizar várias indústrias. $O$ capital de risco é pouco difundido no Brasil e as primeiras tentativas estão sendo esboçadas em alguns pólos tecnológicos, como é o caso de São Carlos. Em São José dos Campos constatou-se uma forte presença governamental e o Ministério da Aeronáutica, por motivos já discutidos, incentivou e privilegiou a participação da indústria nacional nos projetos de seu interesse.

O pólo tecnológico de São José dos Campos não contou com planejamentos explícitos e sistematizados; essa é sua "marca registrada" e o torna um caso único no país, possibilitando uma antecipação da onda que, a partir dos anos 70, implantou pelo mundo os pólos tecnológicos e os Science Parks. Merece especial destaque o pioneirismo de pessoas que souberam aproveitar os exemplos bem-sucedidos de outros países, o que fica exemplificado com a criação do ITA, estruturado a partir da experiência do MIT. Após a instalação do ITA, em 1950, foi criado um Instituto de Pesquisas (IPD/CTA), voltado para a pesquisa aplicada e desenvolvimento tecnológico, que aproveitava em parte a mão-de-obra formada e que atuaria como ponte com a indústria. É interessante observar que a existência dos institutos de pesquisas foi fundamental para o surgimento de empresas. Constatou-se que, quando os sócios dessas empresas eram pessoas físicas, na quase totalidade dos casos eles eram pesquisadores desses institutos.

Outro fator que incentivou a criação de empresas foi a postura favorável do setor de ensino e pesquisas, principalmente o IPD/CTA, que não impunha restrições à criação de indústrias e em alguns casos até a incentivou. Os dirigentes dessas instituições sempre tiveram presente que o desenvolvimento tecnológico necessariamente deveria considerar as condições de mercado e o "ator" principal deveria ser a indústria. Outra preocupação permanente no CTA foi a adoção de uma estrutura educacional que permitisse $o$ domínio da tecnologia por parte das empresas nacionais. Embora os resultados tenham uma maturação mais lenta, hoje eles são visíveis e têm uma magnitude considerável, justificando, pelo menos em parte, os investimentos realizados e permitindo a existência de spin-offs em diferentes setores. Trata-se de uma postura compatível com o desenvolvimento econômico-social do Brasil da época, onde não se efetuavam discussões mais abrangentes sobre os projetos que consumiam uma parcela substancial de recursos públicos. Esse é outro aspecto que merece ênfase especial e não é discutido neste texto.

O quadro III apresenta uma síntese dos dez fatores (colocados na forma de atributos ou ações) 
Quadro III

Fatores responsáveis Pelo Desenvolvimento

Científico-Tecnológico-Industrial de São José dos Campos

\section{Fatores (Atributos ou Ações)}

1. Existência de Escola Superior em Moldes Não Universitários (De excelente nível e com ênfase em engenharia)

2. Tecnologia Estratégica do Ponto de Vista Político e Militar (Tecnologia aeroespacial, bélica e eletrônica avançada)

3. Atuação Decisiva e Contínua do Governo

(Governo atua como financiador de formação de pessoal e das pesquisas e através de seu poder de compra)

4. Ensino Associado a Pesquisas

(Nos níveis de graduação e pós-graduação)

5. Existência de Sinergia Entre Atores da Inovação tecnológica (Formação de recursos humanos em densidade compátivel com projetos planejados e escolha de local fora dos grandes centros - que facilita o intercâmbio)

6. Institutos de Pesquisa Não Restringiram Criação de Empresas (Dirigentes dessas instituições não colocam obstáculos à saída de pesquisadores para a criação de empresas e foram constatados casos de incentivo)

7. Comunidade Científico-Tecnológica Reconhece Papel da Indústria (Tecnologia concebida para ser repassada à indústria a qual, em alguns casos, participa da geração)

8. Existência de Projetos Tecnológicos Próprios (Incentivo, hábil, à tecnologia gerada no país, bom aproveitamento da experiência de outros países e repulsa pelas imitações precipitadas)

9. Existência de Pessoas que Lideram e "Personificam" Projetos (Efeito indutor dessas pessoas e habilidade em romper barreiras político-institucional-burocráticas)

10. Prefeitura Municipal Proporciona Infra-Estrutura

(Postura empresarial da Prefeitura, evitando medidas paternalistas e proporcionando vias de transporte, energia, água, escolas, comunicações e demais itens de infra-estrutura urbana) 
que, no entendimento dos autores, permitiram que São José dos Campos alcançasse seu atual nível de desenvolvimento científico-tecnológico-industrial. Os fatores estruturais, conjunturais e organizacionais apresentados nesse quadro formam um retrato caricatural, que tenta realçar os traços mais marcantes e estáveis, que ficaram evidenciados ao longo da realização desta pesquisa e que contribuíram para que São José dos Campos atingisse seu desenvolvimento. Outros certamente há que não foram considerados. Os fatores apresentados no quadro III não são homogêneos, nem independentes, e nem se procurou hierarquizá-los segundo a sua importância. Contudo, sintetizam a discussão do pólo tecnológico de São José dos Campos e demonstram como foi possível criar uma interação apropriada entre ensino, pesquisa e indústria.

O estudo do pólo tecnológico de São José dos Campos estimulou ainda a reflexão acerca do papel dos modelos de gestão tecnológica. Foi possível descrever um caso onde se constata uma concentração de empresas e instituições de ensino e pesquisa que se relacionam intensamente, dentro de uma área limitada (os limites geográficos do município). Não houve entidades formalmente constituídas que se encarregassem da gestão tecnológica, nem a definição de terrenos ou prédios especialmente destinados a abrigar as empresas que estavam surgindo. Os próprios parceiros desse desenvolvimento tecnológico supriram tais lacunas. Constatou-se a existência de uma política tecnológica implícita, que norteou as ações das diversas entidades. Quanto à questão física, não foram necessários planejamentos imobiliários especiais. As empresas, naturalmente, situavam-se perto uma das outras e próximas às instituições de pesquisa e ensino. Isso provocou um efeito catalisador e criou-se sinergia decorrente da ação dos vários parceiros, como preconizado pelo modelo "pólo tecnológico".

A análise anterior não rejeita a existência de estruturas organizacionais concebidas para favorecer o surgimento de pólos tecnológicos. Simplesmente, foi descrito um caso onde tal estrutura não esteve presente. Contudo, segundo declaração dos entrevistados, uma estrutura leve de gestão tecnológica poderia ter suprido algumas deficiências, tais como:

a) as empresas, mesmo as grandes, tiveram dificuldade em utilizar os laboratórios existentes nas instituições de pesquisa, em virtude de não existir uma sistemática que facilitasse o acesso; b) existe carência no fluxo de informações tecnológicas; $\mathrm{e}$

c) existem carências relacionadas à gestão tecnológica tais como: apoio em propriedade industrial, elaboração em contratos de transferência de tecnologia, ações junto à CACEX, contatos internacionais e outros serviços, principalmente para as pequenas empresas.

A exposição anterior, além de relatar um caso de reconhecida importância, leva a um posicionamento filosófico que deve ser explicitado. Os autores acreditam que a interação pesquisa-indústria-governo deve ser construída a partir de projetos próprios, definidos com base nas condições locais, dando prioridade à indústria, e formando massa crítica científico-tecnológica. Outra preocupação fundamental é definir uma estratégia apropriada que combine a tecnologia importada com aquela desenvolvida no país. A partir dessas premissas podem-se aproveitar as recomendações que figuram em modelos de pólos tecnológicos. Não faz sentido, contudo, adotar por inteiro esquemas concebidos para realidades que não a nossa ${ }^{4}$.

ABSTRACT: The city of São José dos Campos is one of the most important examples of technological and industrial development center of Brazil. The reason is the interaction among teaching, research and industry, keeping the particularities of each activitie and each maturation period. Evidence has shown that the effort of many people and institutions interested in concentrating the capability of the aerospacial and military sectors in the city resulted on the creation and consolidation of a kind of Technological Park that has been discussed on the specialized literature. This article analyses the mechanisms that lead this city into the present stage of development and discusses the process of transformation of research into technological innovation.

KEY TERMS: Science parks, research parks, technology based firms, innovation centers, aerospacial sector.

4. A realização deste artigo foi motivada pela pesquisa recentemente realizada pelos autores sob o título "Aglomerado de empresas de alta tecnologia em São José dos Campos", a qual serviu de base para este trabalho. Essa pesquisa, integrante do Projeto Parques Tecnológicos na América Latina (OEA, FINEP, CNPq, UFRJ/COPPE, USP, INPE), foi coordenada por Silvio Aparecido dos Santos e Jacques Marcovitch, da Universidade de São Paulo (PACTo-IA-FEA), a quem os autores agradecem. 